\title{
O desenvolvimento econômico: uma proposta de abordagem teórica evolucionária e institucionalista
}

\author{
Herton Castiglioni Lopes \\ Professor - Universidade Federal da Fronteira Sul (UFFS) \\ Endereço: Rua Major Antônio Cardoso, 590 - Cerro Largo - Rio Grande do Sul/RS - Brasil \\ CEP: 97900-000 - E-mail: herton.lopes@uffs.edu.br \\ Recebido em 12 de fevereiro de 2014. Aceito em 17 de junho de 2014.
}

\begin{abstract}
Resumo
O trabalho objetiva propor uma abordagem teórica para analisar o desenvolvimento econômico unindo elementos da Teoria da Regulação (T.R.), do antigo institucionalismo de Veblen e da teoria evolucionária neoschumpeteriana. O texto congrega os conceitos de inovação, rotinas e revoluções tecnológicas, demonstrando que o crescimento emerge das firmas ao plano macroeconômico a partir do progresso técnico. Com a teoria da regulação se demonstra que as formas institucionais devem estar adequadas e fornecer o estímulo à inovação tecnológica e aproveitamento das janelas de oportunidade abertas pela revolução em curso. A essa análise, incorpora-se a noção de hábitos de pensamento de Veblen que, no plano microeconômico, representam as rotinas e afetam as inovações no interior das empresas. Os hábitos são ainda o elemento de sustentação da regulação macroeconômica, pois consolidam a configuração das formas institucionais que podem afetar a acumulação de capital e o desenvolvimento tecnológico. Enfim, entende-se o desenvolvimento a partir das formas institucionais, dos hábitos dos agentes, da inovação e do progresso técnico.
\end{abstract}

Palavras-Chave

Desenvolvimento econômico. Neoschumpeterianos. Institucionalismo de Veblen. Teoria da regulação.

\begin{abstract}
The objective of this paper is to propose a theoretical approach in order to analyze the economic development joining it with the Theory of Regulation, the Old Institutionalism by Veblen and the Neo-Schumpeterian Economic Evolutionary Theory. The text congregates the concepts of innovation, routine and technological revolution, showing that the growth depends on the enterprise to the macroeconomic planning trough the technical progress. With the Regulation Theory, the instructional ways have to be adequate to supply the encouragement to the technological innovation and to take advantage of the opportunities open by the current revolution. To this analysis, the notion of Veblen's thought habits are added, which in the macroeconomic development plans they represent the routines and affect the innovation inside the company. The habits are still the macroeconomic regulation maintenance, because it strengthens the confirmation of institutional ways that can affect the accumulation of capital and the technological development. In conclusion, the development can be understood throughout institutional ways of agent habits of innovation and technical progress.
\end{abstract}




\section{Keywords}

Economic development. Neo-Schumpeterian. Institutionalism by Veblen. Theory of regulation.

\section{JEL Classification}

O10. 043. B52.

\section{Introdução}

No campo de estudo econômico, o desenvolvimento sempre foi o foco de análise, e seus determinantes vêm sendo tratados de inúmeras formas pelas diversas doutrinas econômicas. A preocupação desse texto não é diferente, pois busca interpretar o fenômeno a partir de um mix de referenciais teóricos. Nessa proposta de trabalho, objetiva-se propor uma abordagem teórica para analisar o desempenho econômico unindo elementos da teoria evolucionária neoschumpeteriana, da Teoria da Regulação (T.R.) e do antigo institucionalismo de Veblen.

Embora cada uma das teorias possa ser vista como um modelo de análise do crescimento, quando unidas se tornam um ferramental analítico ainda mais sólido. Isso porque a explicação do desenvolvimento deve incorporar: a) uma abordagem heterodoxa de como acontece a inovação no interior das firmas; b) uma análise que explique o desenvolvimento através do progresso tecnológico que ocorre mediante a inovação e proporciona saltos de produtividade; c) uma análise que dê conta de observar como a configuração macroeconômica e as políticas de estado podem incentivar ou prejudicar o progresso das nações; d) enfim, uma explicação que incorpore elementos micro, macroeconômicos e institucionalistas na avaliação da performance dos países. Tendo essas preocupações em mente, a união de conceitos presentes na teoria da regulação, no institucionalismo derivado de Veblen e na teoria evolucionária neoschumpeteriana será capaz de oferecer subsídio para se avançar rumo à melhor compreensão dos fatores que afetam os diferentes desempenhos das economias ao longo da história.

A T.R. contempla uma análise macroeconômica do funcionamento das economias capitalistas. Em especial, o conceito de formas institucionais descreve as regularidades do plano microeconômico que se manifestam no plano macro, assegurando a regularidade da acumulação do capital e o crescimento econômico. Mesmo sendo uma 
abordagem consistente, o desenvolvimento não pode ser compreendido sem uma teoria do comportamento das firmas e sua contribuição para o progresso tecnológico. A teoria neoschumpeteriana cumpre adequadamente esse papel, tanto no âmbito das firmas, incorporando conceitos da biologia, como do ponto de vista agregado, quando descreve o papel das revoluções tecnológicas, dos paradigmas tecnoeconômicos, e da trajetória tecnológica no desempenho das nações.

Finalmente, a teoria institucionalista derivada de Veblen contribuiu para explicação da inovação no interior das empresas e disseminação do progresso técnico, assim como se alinha com a definição do modo de regulação vigente. Ela é proposta como elo entre o ambiente micro e macroeconômico, porque os hábitos exercem influência e sustentam o comportamento dos agentes no interior das empresas e na sociedade. Os hábitos ainda asseguram a configuração das formas institucionais, sem as quais o comportamento das firmas ficaria carente de referência macroeconômica.

Com vistas a atingir a proposta de trabalho, ou seja, unir elementos evolucionários e institucionalistas para interpretar o desempenho, inicia-se o estudo com a teoria neoschumpeteriana, apresentando-se sua abordagem microeconômica e os conceitos de revoluções tecnológicas, paradigmas tecnoeconômicos e janelas de oportunidade. Em seguida, trata-se da teoria da regulação, com especial enfoque no conceito de formas institucionais (seção 3). A seção 4 descreve a noção de instituições de Veblen a partir dos hábitos de pensamento. Eles são elemento chave para compreender as regularidades no interior das firmas (inovação e progresso técnico) e na sociedade (comportamento humano), mantendo a estabilidade do modo de regulação ou demandando a reconfiguração das formas institucionais. A seção 5 apresenta a integração dos conceitos trabalhados nas seções anteriores, explicitando as relações entre as três teorias e como suas abordagens alinham-se na explicação do desenvolvimento. Finalmente, têm-se as considerações finais (seção 6). 


\section{Neoschumpeterianos: abordagem microeconômica evolucio- nária e os conceitos de revoluções tecnológicas, paradigmas tecnoeconômicos e janelas de oportunidade}

Os neoschumpeterianos são assim chamados porque resgatam o pensamento de Schumpeter ao enfocar a inovação como fenômeno fundamental do desenvolvimento. Em Schumpeter a inovação altera o equilíbrio estático do sistema econômico de forma a modificar a mera reprodução das condições de produção vigentes (fluxo circular). As inovações são tratadas como um fenômeno interno ao modo de produção e deflagradas pelos produtores individuais que, procurando alternativas para aumentar sua lucratividade, acabam desenvolvendo as novas combinações. Nesse processo, destaca-se o papel do crédito e do empresário, responsável por colocar em práticas as inovações e desencadear as mudanças endógenas que geram os ciclos de crescimento (Schumpeter, 1984; 1985).

A exemplo de seu precursor, os neoschumpeterianos enfatizam a incorporação de elementos evolucionários à teoria econômica, utilizando-se de conceitos apropriados da biologia para explicar o desenvolvimento. Richard R. Nelson e Sidney G. Winter são autores que fizeram sistemático esforço para compor uma análise microeconômica nessa perspectiva teórica. Uma série de conceitos desbravadores da tradição evolucionária foram publicados na obra "In search of useful theory of innovation" de 1977. No entanto, o trabalho seminal na ótica evolucionista é o livro "An evolutionary theory of economic change", de 1982.

Nas análises de Nelson e Winter (2005), as firmas recebem atenção especial por ser o local onde acontece a inovação e o desenvolvimento de rotinas, que estabelecem o comportamento dos agentes no processo produtivo. ${ }^{1}$ As firmas são o organismo em evolução, pois suas rotinas e conhecimento acumulado resultam dos mecanismos de seleção e adaptação que se processam ao longo do tempo. Nessa perspectiva, a metáfora evolucionista serve exatamente para explicar o desenvolvimento e prosperidade das inovações e a consolidação das rotinas mais eficazes. Firmas com rotinas mais adequadas às condições de mercado serão as com maior possibilidade de sobrevivência e mais aptas a adquirir maior participação no mercado (market share).

1 Por isso, Neoschumpeterianos convergem com Simon (1986) em sua proposta de racionalidade. Admitem que as agentes não conseguem maximizar os benefícios de suas escolhas, mas procuraram as opções mais adequadas para os problemas que ocorrem em determinados contextos. 
Possas (2008) sistematiza a análise biológica traçando sua relação com a economia. Os organismos individuais (fenótipos) correspondem, na análise econômica, às firmas com características específicas que definem as condições de sobrevivência a ambientes hostis. As populações são os mercados ou indústrias e trata-se do lócus onde acontece o processo de seleção das empresas mais competitivas, que crescem e se apoderam de maior parte do mercado. Os genes ou genótipos são as rotinas, elementos relativamente estáveis ao longo do tempo e que permitem definir as características das empresas. O processo de mutação representa-se pela inovação, que gera novas rotinas com vistas a solucionar os problemas que prejudicam o desempenho das empresas. Enfim, a aptidão corresponde à lucratividade, como resultado do processo de inovação e das rotinas mais eficientes.

No modelo proposto, as rotinas e capacidade de inovação são determinadas pelas experiências vivenciadas pelas empresas. Para Zawislak (1996) as firmas estão em constante processo de aprendizagem, acumulando competências que permitem criar e modificar rotinas de acordo com as situações observadas. Os estímulos provêm do mercado, pois, ao fazerem parte de um ambiente competitivo, as empresas procuram, através de um processo de busca (search), incorporar inovações que modificam as rotinas. Um processo de adaptação ao ambiente e que visa à solução dos problemas aleatórios que acontecem ao longo do processo produtivo. Existe ainda um feedback entre as rotinas e a inovação, pois ao mesmo tempo em que a inovação cria novas rotinas, estas, ao estarem consolidadas e adaptadas a determinados contextos, acabam refletindo nas futuras inovações. As rotinas e inovações são, portanto, os determinantes da sobrevivência e sucesso das firmas no mercado porque estabelecem a forma predominante de fazer as coisas e como elas podem ser alteradas.

Além da abordagem microeconômica, a teoria evolucionária neoschumpeteriana apresenta estudos mais agregados, que se desprendem do plano das firmas para explicar os diferenciais de desenvolvimento das nações. Carlota Pérez e Christopher Freeman se propuseram a interpretar o desenvolvimento a partir das grandes inovações que acontecem nos países capitalistas. Fazendo alusão aos ciclos econômicos, identificados por Nikolai Kondratieff ${ }^{2}$ nos anos 1920, a teoria dos autores trata das inovações radicais, sendo elas as

2 Maiores esclarecimentos podem ser encontrados em Pérez (1983). 
responsáveis pelas ondas longas de crescimento que duram cinco ou seis décadas.

Tratando dessas inovações, Pérez (1992; 2001; 2004; 2009) ${ }^{3}$ discute o conceito de Revoluções Tecnológicas como responsável pelas possibilidades dos países menos desenvolvidos avançarem rumo às nações de ponta. Partindo da tradição de Schumpeter, a autora afirma que uma revolução é: "un poderoso y visible conjunto de tecnologías, productos e industrias nuevas y dinámicas, capaces de sacudir los cimientos de la economía y de impulsar una oleada de desarrollo de largo plazo" (Pérez, 2004, p.31). Existiram cinco revoluções tecnológicas (a revolução industrial; a era do vapor e das ferrovias, a era do aço e da eletricidade; a era do automóvel e da produção em massa; a era da informática e da sociedade do conhecimento) que se disseminaram moldando as condições de produção nos diferentes países.

A revolução tecnológica está associada a uma série de inovações que se vinculam à utilização de um fator-chave, uma nova descoberta que revoluciona os métodos de produção. As novas tecnologias permitem o surgimento de novas indústrias ou fazem com que as indústrias antigas sejam redefinidas. Com novas indústrias e tecnologias, a infraestrutura acaba sendo modificada para dar conta das novas demandas produtivas. Finalmente, todas essas transformações fazem emergir um novo paradigma produtivo, ao qual a autora (Pérez 2001, 2004, 1983) chama de paradigma "tecnoeconômico". ${ }^{4}$ O paradigma tecnoeconômico é um roteiro para inovação, um guia para decisão

3 Pérez (2004) desenvolveu um modelo histórico-analítico que possibilita identificar as fases de desenvolvimento pelas quais passam as economias capitalistas. Para a autora, uma revolução tecnológica passa por duas etapas distintas: um intervalo de instalação e outro de desprendimento, cada qual durando cerca de 20 ou 30 anos. O primeiro intervalo subdividese em dois períodos: um de irrupção, quando acontece um grande salto na produtividade das tecnologias relacionadas ao novo paradigma produtivo e outro chamado de frenesi, quando o comportamento frenético do capital financeiro, em busca de lucros associados a novas tecnologias, faz surgir bolhas financeiras. Com a crise aparece a necessidade de regulamentação estatal e reestruturação institucional, que gera um intervalo de acomodação abrindo possibilidades para uma segunda etapa: a de desprendimento ou difusão, que se subdivide em uma fase de sinergia, com expansão do potencial inovativo e de mercado e uma fase de maturidade, com oportunidades de investimento decrescentes e capital ocioso que se movimenta em busca de maiores lucros.

4 Em um contexto microeconômico, e traçando paralelos com a noção de paradigmas científicos de Thomas Khun (1992), Dosi $(1988,1993)$ propôs o conceito de paradigma tecnológico. Nele as inovações associadas a novas tecnologias são vistas muito mais como incrementais e relacionadas ao âmbito de atuação das empresas. Embora seja reconhecida a contribuição desse autor, a definição de paradigma tecnoeconômico é mais abrangente, pois, segundo Conceição (2001), o conceito incorpora a dimensão técnica, econômica e institucional, que afeta as inovações e o progresso tecnológico. 
dos empresários, inovadores, gerentes, administradores e investidores quando buscam maior eficiência produtiva (Pérez, 2001). Trata-se de um tipo ideal de organização do sistema produtivo, o estabelecimento de um sentido do que se acredita ser a melhor opção (ou ótimo) tecnológica (o) para aproveitar o aparecimento do fator-chave (Pérez, 1983). Assim, é definido como:

[...] um modelo de óptima práctica constituido por un conjunto de principios tecnológicos y organizativos, genéricos y ubicuos, el cual representa la forma más afectiva de aplicar la revolución tecnológica y usarla para modernizar y rejuvenecer el resto de la economía. Cuando su adopción se generaliza, estos principios se convierten en la base del sentido común para la organización de cualquier actividad y la reestructuración de cualquier institución (Pérez, 2004, p. 41 ).

A revolução em curso e o novo paradigma serão essenciais na compreensão do que leva os países a um salto qualitativo de desenvolvimento. A possibilidade de convergência entre os níveis de crescimento dos países desenvolvidos (líderes) e em desenvolvimento (seguidores) foi tratada em Abramovitz (1986). Para ele, devido às diferenças de produtividade, existem possibilidades de os países avançarem (forging ahead) e alcançarem os desenvolvidos (catching $u p$ ). Por outro lado, muitos podem ser ultrapassados (falling behind) e ficarem excluídos da onda de crescimento em curso. Nos trabalhos de Carlota Perez, o que determina o avanço dos países é a sua capacidade em aproveitar as janelas de oportunidade que se abrem em cada revolução.

A janela de oportunidade e o catching up se relacionam com a fase da revolução em vigência e com trajetória tecnológica que se desenha quando emergem as novas tecnologias. Fazendo paralelos com a teoria do ciclo de vida do produto, observa-se que as inovações tecnológicas tendem a seguir um curso similar desde o seu surgimento. $\mathrm{Ou}$ seja, passam por quatro fases. Na primeira delas acontece uma inovação radical e o aparecimento de um novo produto que sustenta o desenvolvimento de uma indústria. Na segunda e terceira, as novas 
tecnologias passam por uma sequência de inovações incrementais, visando melhorar a qualidade, a produtividade e a posição dos produtores no mercado. Enfim, na quarta fase a tecnologia entra em sua fase de maturação, com a inovação e a utilização das tecnologias já amplamente difundidas, reduzindo as possibilidades de lucro empresarial (Pérez e Soete, 1988; Pérez, 2001; 2004).

Justamente nos períodos iniciais da revolução tecnológica é que acontecem as melhores oportunidades para os países seguidores utilizarem-se das novas tecnologias. Trata-se de um momento crucial, quando se abre a janela de oportunidade para os países menos desenvolvidos alcançarem as grandes potências. Isso porque é um período de abertura de novos mercados e um momento em que as inovações associadas às novas tecnologias apresentam maior rentabilidade. Apesar da importância de se ingressar nas primeiras fases de uma nova revolução, as anteriores são relevantes para aprendizagem e criação de infraestrutura necessária às revoluções seguintes. Por isso, Perez (1992) afirma que a fase de maturação de uma tecnologia, junto com a fase de surgimento das novas, é um momento de dupla oportunidade tecnológica.

\section{A regulação macroeconômica e o conceito de formas institucionais}

A teoria da regulação procura explicar como acontecem as crises e as regularidades que se processam no modo de produção capitalista viabilizando, ou não, a continuidade da acumulação de capital. Segundo Conceição (1987), a teoria surge a partir dos problemas observados nas economias capitalistas nos anos 1970 (estagflação), criando a necessidade de maiores estudos sobre os problemas e as regularidades que acontecem ao longo da reprodução do capital. ${ }^{5}$ Sua grande vantagem enquanto teoria do crescimento é o fato de permitir uma integração dos fenômenos que se processam no plano micro e macroeconômico.

\footnotetext{
5 A partir de uma interpretação marxista, desenvolveu-se na França, na Alemanha e nos Estados Unidos, um arcabouço teórico que permitiu avançar na compreensão da crise e da prosperidade. Atualmente, a T.R. está vinculada a uma série de autores, muitos citados ao longo desse texto.
} 
Nos regulacionistas o crescimento equilibrado acontece porque a forma de regulação garante a estabilidade na reprodução do capital. Nesse sentido, existem três conceitos fundamentais. Em primeiro está o de regime de acumulação, que se trata das regularidades que asseguram a acumulação do capital. Em segundo, tem-se o conceito de regulação, que são as mediações institucionais que mantém a coesão social e a coerência macroeconômica, mesmo com as contradições presentes no modo capitalista de produção. Em terceiro, temos o conceito de formas institucionais. Elas representam um nível intermediário entre o regime de acumulação e a regulação. Ou seja, existem características específicas em um regime de acumulação definidas a partir das relações sociais. As formas institucionais são instância de ligação entre esses dois níveis.

$\mathrm{Na}$ macroeconomia regulacionista, as instituições são importantes na compreensão da organização econômica e na explicação do comportamento dos agentes, superando a versão tradicional de equilíbrio e maximização das abordagens ortodoxas. ${ }^{6}$ A T.R. propõe que o comportamento dos indivíduos relaciona-se com a configuração das formas institucionais, fornecendo um elo entre o ambiente micro e macroeconômico (Boyer; Saillard, 2002). Como afirma Bruno (2004): [...] resultam de um processo de codificação de compromissos sociais, convenções, regras ou procedimentos socialmente aceitos como imprescindíveis à coesão social e à coerência macro-dinâmica do conjunto do sistema (Bruno, 2004, p. 44). Ou seja, são a codificação de uma ou várias relações sociais fundamentais (Boyer, 1990).

\footnotetext{
${ }^{6}$ Ao invés do conceito de racionalidade proposto pela ortodoxia tradicional, interessa aos regulacionistas o conceito de racionalidade contextual ou racionalidade situada. Essa concepção admite que os agentes adotem determinadas convenções que estejam em acordo com a sociedade e seu funcionamento. Ou seja, a partir do contexto no qual se encontram, os indivíduos adotam posturas racionais, no sentido de seguirem as convenções sociais. Portanto, ser racional significa adotar atitudes que estejam de acordo com o ambiente e com as interações sociais do momento. Para Bruno (2004), a racionalidade é situada ou contextual quando três condições se fazem presentes: 1) quando o comportamento do agente pode ser interpretado como estratégico ou relacional, porque diz respeito a práticas previstas para o futuro; 2) quando o comportamento racional se explica pelo seu contexto, descrito através de uma quantidade de experiências que formam um modelo cognitivo semelhante; e 3) quando a racionalidade situada está ligada a emergência de atores coletivos (estruturas coletivas de representação e decisão) que estabelecem a coordenação entre os agentes sem a necessidade de excluir os interesses mais individualistas. A partir dessas três condições, a racionalidade situada se torna procedimental; com relação aos procedimentos adotados pelos agentes em determinados contextos. Para Bruno (2004, p.113), "[...] se refere a uma forma de proceder que está necessariamente referenciada em estruturas, organizações, convenções e instituições específicas".
} 
Se as formas institucionais não representarem os padrões comportamentais dos agentes, pode-se esperar uma crise que exigirá uma nova forma de regulação. Do contrário, a coerência micro e macroeconômica mantêm a estabilidade e o crescimento, em conformidade com as características da acumulação de capital em vigor. Com inspiração em Marx, as formas institucionais são tratadas como as relações fundamentais do modo de produção capitalista, sendo elas: a forma de competição, a gestão monetária, a relação salarial, a forma de estado e de inserção no regime financeiro internacional.

Como o sistema de mercado funciona a partir da interação entre as unidades produtivas, inevitavelmente existe uma forma de competição. Para Hollard (2002), a forma de concorrência pode ser identificada a partir de inúmeras variáveis, tais como o tamanho do produto, a escala das companhias, as relações envolvidas entre as empresas nos diferentes estágios do processo, a relação entre compradores e vendedores, etc. Tradicionalmente, pode ser relacionada com a maior ou menor concentração de mercado nas mãos de poucas empresas. Por isso, para Boyer (1990) podem ser observadas características mais concorrenciais ou de monopólio.

A relação entre as unidades econômicas acontece a partir das trocas. Por isso, é preciso um elemento para estabelecer essa conexão. Então, a T.R. apresenta a forma institucional de restrição monetária. Guttmann (2002) afirma que os regulacionistas reconhecem a moeda como diretamente relacionada à atividade econômica, e que a grande contribuição da escola é exatamente compreendê-la como uma instituição social. ${ }^{7}$ Indo além da simples definição de moeda, os regulacionistas afirmam que a gestão monetária incorpora todas as características do sistema financeiro nacional e como o mesmo se inter-relaciona com as finanças internacionais.

Não existe como analisar o modo de produção sem uma relação entre capitalistas e trabalhadores. Nesse caso, a Teoria da Regulação propõe a forma relação salarial, que estabelece uma norma social de exploração (extração da mais-valia) a partir da compra e venda da força de trabalho. Boyer (1990) afirma que ela demonstra como serão apropriados os excedentes da atividade econômica e que sua caracterização condiz com os diferentes tipos de organização do traba-

7 O destaque na tradição monetária fica por conta de Aglietta e Orleans (1990). Na obra $A$ Violência da Moeda haviam observado que essa forma institucional apresenta tendência em se sobrepor às demais.

Estud. Econ., São Paulo, vol.45, n.2, p.377-400, abr.-jun. 2015 
lho, do modo de vida dos trabalhadores e as modalidades de relação que ocorrem na reprodução dos assalariados. ${ }^{8}$ De uma forma mais objetiva, Boyer (2002b) define a wage-labour nexus como o conjunto legal de condições institucionais que regulamentam o uso do trabalho assalariado de acordo com o modo de vida da classe operária.

A T. R. ainda observa a necessidade de análise da forma estado e de inserção do país no regime internacional. Segundo Boyer e Saillard (2002), a forma estado analisa como a organização pública se relaciona com a atividade econômica, criando compromissos institucionalizados para evolução das despesas e receitas. ${ }^{9}$ Assim, a análise regulacionista pode identificar um conjunto de regras e regularidades que emergem a partir da interação estado-economia e afetam a evolução das finanças públicas. A inserção no regime internacional, por seu turno, diz respeito à conjunção de regras que delimitam as relações entre os Estados-Nação e o resto do mundo, preocupando-se com as trocas de mercadorias (localização da produção) e com as relações financeiras entre nações.

É importante reforçar que as formas institucionais representam o modo como uma nação regulamenta suas atividades macroeconômicas. Porém, elas também captam as regularidades do nível microeconômico e as transportam para o plano macro porque são resultado de padrões habituais de comportamento. Por isso, relacionam-se com a forma de organização da produção e o desempenho econômico conforme se advoga no texto.

\section{As instituições, os hábitos e o comportamento a partir do institucionalismo de Veblen}

Assim como as abordagens anteriores, Thorstein Veblen dedicou boa parte de seus escritos a desenvolver uma doutrina alternativa à or-

8 Segundo o autor, cinco componentes caracterizam as configurações históricas da relação entre capital e trabalho. São elas: o tipo de meios de produção, a forma da divisão social e técnica o trabalho, a modalidade de mobilização e de vínculo dos assalariados com a empresa e o modo de vida do assalariado, que se relacionada à aquisição de mercadorias ou a utilização de serviços coletivos fora do mercado.

9 Não por acaso os regulacionistas analisam o papel do welfare state no crescimento econômico dos anos dourados. Para André (2002), o estado do bem-estar representa uma série de compromissos sociais, que incluem políticas educacionais, de emprego, de renda, entre outras. 
todoxia convencional. Inconformado com a incapacidade da teoria tradicional em explicar a mudança, o autor recorreu a teorias evolucionárias por inspiração darwiniana, para esclarecer as transformações que se processavam na economia e na sociedade. Ao fazer isso, ofereceu um importante ponto de partida para o desenvolvimento da teoria institucionalista, mesmo que o termo instituições conte, atualmente, com uma diversidade de enfoques metodológicos. Seu destaque é uma visão de Economia como ciência evolucionária, muito diferente das análises que enfocam o equilíbrio do sistema (Hodgson, 1993). ${ }^{10}$

No institucionalismo de Veblen as instituições são hábitos estabelecidos pelo pensamento comum, de forma generalizada pelos homens (Veblen, 1919). Porém, a compreensão de sua proposta implica compreender a gênese dos hábitos, bem como os fatores que os afetam e modificam. Os hábitos estão relacionados com os instintos, que são os fins últimos da ação humana. Para alcançar os objetivos finais, sejam quais forem, é preciso definir um meio, uma forma de ação ou padrão de comportamento. Esse meio é determinado pelos hábitos que se formam ao longo do tempo. Ou seja, à medida que os seres humanos desenvolvem meios para atingir seus objetivos finais, se estabelece um processo de habituação. Definidos os comportamentos, eles se tornam um reforço para os hábitos e para as instituições. Hodgson (2010) demonstra que existe uma forte inter-relação entre os hábitos e o comportamento humano, pois ações repetidas são fundamentais para reforçar os hábitos. Contudo, é importante observar que os hábitos não levam, necessariamente, a uma ação, pois se tratam de um comportamento potencial que pode ser desencadeado por estímulos externos (Dewey, 1922).

Ao estabelecerem o comportamento, deduz-se que os hábitos afetam o processo de deliberação e as crenças dos agentes. Em outras palavras, as ações se respaldam nos hábitos, nas crenças e numa racionalidade que depende da habituação dos indivíduos. ${ }^{11}$ Nesse processo, os hábitos se tornam o alicerce das instituições. Hodgson (2006;

${ }^{10}$ O prefácio da Teoria da Classe Ociosa, de Veblen (1983), traz o pensamento de Jacob Oser sobre a essência do pensamento institucionalista. Para os institucionalistas, economia deveria ser analisada não em partes, mas como uma totalidade e a partir de um contexto evolucionário (darwinismo). Por isso, não acreditam em uma ordem harmônica e nas análises de equilíbrio que tendem ao melhor desempenho possível. Pelo contrário, advogavam a intervenção do Estado para regular os conflitos e obter melhor distribuição de recursos (Oser, 1983).

${ }^{11}$ Uma síntese sobre a relação entre o comportamento humano, os hábitos, as crenças e as instituições foi apresentada em Lopes (2013). 
2007b) afirma que ao se reproduzir hábitos compartilhados de pensamento criam-se instituições fortes, mecanismos de conformismo e acordos de caráter normativo. Para o autor, os hábitos são as matérias que constituem as instituições, proporcionando-lhes maior durabilidade, poder e autoridade normativa.

Como as instituições afetam a conduta dos agentes, Hodgson (2002) propõe o conceito reconstitutive downward causation, expressando a ideia de que existe um forte sentido causal dos níveis mais elevados para os níveis individuais, ou seja, as instituições influenciam os indivíduos, podendo agir no sentido de modificar a sua mentalidade e forma de agir (causação descendente e reconstitutiva). ${ }^{12}$ Contudo, a relação não é unidirecional e, por isso, recentemente o autor se propôs substituir o conceito pelo termo reconstitutive downward effect. Segundo Hodgson (2011), acontece um efeito de reconstituição dos níveis superiores para os inferiores quando um sistema, que contém elementos de nível inferior, cria ou reafirma condições relacionadas à natureza dos elementos do nível mais baixo. Assim, indivíduos podem modificar as instituições, mas as instituições exercem uma influência importante sobre os agentes, uma vez que são um conjunto de regras que se respaldam em hábitos coletivos.

Com essas proposições, observa-se claramente que os hábitos podem ser o elemento de mudança ou inércia institucional. Em um contexto darwiniano, a teoria de Veblen demonstra que a mudança econômica ou social é uma transformação institucional que acontece pela alteração dos hábitos mentais. Como afirma Veblen (1983), a mudança não é um processo simples e fácil. Pelo contrário, opera a partir de um processo de seleção e adaptação das instituições ao ambiente em análise. Esse argumento evolucionário ganha relevância em Hodgson (1997b, 142), ao afirmar: "A evolução socioeconômica é considerada como um processo de selecção que opera sobre as instituições e tem nelas a sua unidade de selecção, combinado com um processo simultâneo de adaptação, quer dos indivíduos, quer das instituições ao seu ambiente comum".

\footnotetext{
12 Em Veblen, a relação entre instituições e indivíduos fica clara a partir dos hábitos mentais. Contudo, dentre os antigos institucionalistas, essa visão foi compartilhada também por John R. Commons ao afirmar que uma instituição é "[...] uma ação coletiva que controla, libera e amplia a ação individual” (Commons, 1931, p. 1). Por isso, em determinadas circunstâncias, os indivíduos se tornam mais poderosos devido às instituições do que sem elas e afetam o próprio Estado, demandando desse agente políticas que estejam de acordo com o pensamento da coletividade.
} 


\section{O desenvolvimento econômico: unindo elementos regulacionis- tas, Neoschumpeterianos e Veblenianos}

A integração das ideias trabalhadas anteriormente oferece uma abordagem consistente, com contribuição significativa para explicar como se processa o desenvolvimento econômico. Embora essa análise seja importante para todas as nações, ganha relevância para o caso dos países que não são os precursores da revolução tecnológica. Nesse caso, a teoria neoschumpeteriana propõe o conceito paradigma tecnoeconômico que auxilia a interpretar como os países podem alcançar o desenvolvimento aproveitando-se das oportunidades decorrentes dos novos paradigmas produtivos. Como ressalta Perez (2001, 2004), é no período em que ocorre o "boom" tecnológico que se abrem as janelas de oportunidade para o catching up dos países que ingressam na nova revolução produtiva. Esse momento é determinante porque os mercados para novos produtos estão em expansão, a aprendizagem está ocorrendo simultaneamente em diversos lugares e as possibilidades de retorno são maiores.

Esta abordagem não estaria completa sem observar como as firmas podem aproveitar-se das novas tecnologias. Daí a necessidade de uma análise evolucionária que explique como as empresas, a inovação e rotinas se afirmam como elementos da mudança e do desenvolvimento. Como descreve a metáfora evolucionária é um processo em que operam mecanismos de seleção e adaptação, altamente dependente da trajetória histórica, que molda as condições de sobrevivência das empresas em determinado período e afeta o desempenho das diferentes nações.

Dada a importância da abordagem evolucionária, deve-se questionar: como ela se relaciona com a Teoria da Regulação com vistas a explicar o desenvolvimento? Mais especificamente, em que aspectos a inovação, as rotinas e a revolução tecnológica se relacionam com a proposta da T.R.? Pelo que foi exposto, pode-se deduzir que o desenvolvimento tecnológico, a inovação e as rotinas são altamente dependentes da forma de regulação do sistema, que acontece via instituições ou a partir configuração das formas institucionais. Coriat e Dosi (2007, p. 8) afirmam "[...] an evolutionary story is comfortable with complementary institutional factors [...]. Por isso a importância de se observar como as regularidades que se processam no plano micro e se manifestam no plano macro afetam as rotinas, as inovações e o progresso técnico. 
A relação entre e o desenvolvimento tecnológico e as formas institucionais foi explicitada em Faria (2001). Para o autor, um modo de desenvolvimento é resultado de um processo histórico (plano macro -histórico), que resulta de um regime de acumulação em interação com o modo de regulação (plano sistêmico) e padrão tecnológico. $\mathrm{Ou}$ seja, um processo que se manifesta a partir da acumulação do capital e das inovações, que afetam e são afetadas pela configuração das formas institucionais (plano institucional). Nessa perspectiva, a própria tecnologia é uma instituição; a base material da sociedade que resulta do desenvolvimento técnico e científico e da sua aplicação ao modo vida e de subsistência da sociedade. Para Amable (2002) a coerência de um sistema de técnicas com a configuração das formas institucionais é o que define um regime de crescimento.

A regulação e o avanço tecnológico devem estar em sintonia para que o desenvolvimento econômico não seja comprometido. Em outras palavras, as formas institucionais devem estar adequadas para promover o crescimento sustentado, que acontece com a acumulação de capital e progresso tecnológico. Do contrário, podem gerar instabilidade, crises e depressões macroeconômicas (Coriat e Dosi, 2007). Os exemplos são claros: a relação salarial afeta a repartição do excedente entre lucros e salários, estabelecendo a demanda para os produtos da revolução em curso. ${ }^{13} \mathrm{~A}$ forma concorrência cria os incentivos ao progresso tecnológico a partir do grau de competição observado nos mercados. A gestão monetária, ao incluir todo regime monetário-financeiro, traz repercussões significativas sobre os investimentos produtivos (visão pós-keynesiana) e a propensão à inovação. A relação do país com o exterior repercute de forma importante sobre as possibilidades de inovação e progresso tecnológico porque a inserção no regime internacional define os fluxos financeiros e de mercadorias entre as nações, afetando não apenas a gestão monetário-financeira, mas a forma competição no mercado interno.

Se essas formas institucionais são fundamentais para inovação e tecnologia, o estado ${ }^{14}$ aparece com papel ainda mais relevante porque,

${ }^{13}$ Foi o que aconteceu nos anos dourados, quando os ganhos de produtividade foram repartidos com os trabalhadores, gerando uma demanda capaz de absorver os produtos do progresso técnico em curso.

${ }^{14} \mathrm{~A}$ forma estado está diretamente relacionada à configuração das demais formas institucionais. Boyer (1990) menciona que as formas de relação salarial e concorrência interferem nas transferências sociais e nas despesas públicas. Por outro lado, as regras de direito estabelecidas pelo próprio Estado são importantes na gênese das formas institucionais (ex.: custos com salários, regras de concorrência, etc.). Desta forma, o Estado acaba assumindo papel de 
além de ser o responsável por uma série de incentivos à acumulação de capital e progresso técnico, tem o poder de reconfigurar a forma de regulação predominante e estabelecer uma política macroeconômica que mantenha o crescimento estável e evite os ciclos de crise, recorrentes das economias capitalistas. Esse agente pode assumir papel ativo no processo de desenvolvimento, ou passivo, conforme se tem visto nas ideologias neoliberais. Dessa discussão, surgem os conceitos de "Estado Circunscrito" e "Estado Inscrito". O primeiro, exemplificado pelo caso da França no período que vai da revolução francesa até a segunda grande guerra, diz respeito a um Estado limitado ou restrito a uma economia como espaço autônomo ou independente. Trata-se de admitir a supremacia do mercado em relação ao estado e reconhecer que o desenvolvimento deriva do liberalismo, devendo o estado intervir o mínimo possível no sistema econômico. Já o segundo, no qual se caracteriza a economia francesa após a segunda guerra, refere-se a um Estado inserido na atividade econômica e que se caracteriza por duas inovações: a institucionalização do salário indireto e a concepção de coordenação entre gestão monetária e política macroeconômica (André, 2002). Nesse último caso, o estado apresenta-se como "embedded" na atividade econômica e assume uma série de compromissos que se tornam institucionalizados. Esses compromissos funcionam como estruturas, servindo de guia para a população e grupos sociais. ${ }^{15}$

Visto como a regulação e o conceito de formas institucionais são importantes para inovação e progresso técnico, resta observar como o institucionalismo de Veblen pode contribuir com as duas abordagens e como pode complementar a compreensão do desenvolvimento. Primeiramente: como relacionar a teoria evolucionária com o institucionalismo de Veblen? Ou mais precisamente, que conceitos são mais importantes para explicar o desempenho? Basta observar que as rotinas e a inovação são altamente influenciadas pelos hábitos de pensamento. No plano microeconômico, o comportamento dos agentes, em quaisquer das três abordagens mencionadas, não pode ser explicado pelos modelos tradicionais porque as escolhas, especialmente as que dizem respeito às inovações, geram resultados incertos

grande relevância no regime de acumulação, sendo determinante na sua ascensão ou declínio. Por conseguinte, os investimentos em inovação e as decisões sobre a ampliação da capacidade produtiva acabam afetados.

15 Para André (2002), a noção de "estado inscrito" se assemelha ao welfare state. Essa forma institucional se propõe a cumprir uma série de compromissos em nome de grupos ou de indivíduos, tais como políticas de educação, de emprego, de relações industriais, de habitação, entre outras. 
que não podem ser previstos em um ambiente complexo como o de mercado. Não é por acaso que Hodgson (2010) afirma serem os hábitos mais consistentes na explicação do comportamento humano que as premissas tradicionais de racionalidade.

$\mathrm{Na}$ teoria de Veblen, as instituições estão relacionadas a formas de pensar e agir coletivamente; por isso não podem ser tratadas apenas como regras ou normas formais. Este é o caso das rotinas, que nem sempre estão explícitas em manuais ou regras operacionais criadas dentro das organizações. Pelo contrário, as rotinas apresentam estabilidade porque são hábitos produtivos dos indivíduos. Mesmo a inovação, com retornos incertos, é a afetada pelas rotinas e aprendizagem acumulada ao longo do tempo. Fica clara a convergência com as ideias de Veblen, que procura explicar a mudança a partir de um processo evolucionário de seleção e adaptação, em que a unidade de análise pode ser as instituições ou os indivíduos e sua forma de pensar. No caso da teoria neoschumpeteriana, são as próprias rotinas e a inovação que passam por um processo evolutivo.

Enfim, como a Teoria da Regulação e o conceito de formas institucionais podem se relacionar com o institucionalismo de Veblen? A esse respeito, os regulacionistas afirmam que a configuração específica das formas institucionais reflete os padrões relativamente estáveis de comportamento dos agentes no plano microeconômico. As formas institucionais manifestam as regularidades no plano dos agentes que se transportam para o plano macroeconômico porque elas próprias são resultado de hábitos. Representam a institucionalidade das relações que garantem a estabilidade de um regime de acumulação, resultando [...] de um processo de codificação de compromissos sociais, convenções, regras ou procedimentos socialmente aceitos como imprescindíveis à coesão social e à coerência macrodinâmica do conjunto do sistema (Bruno, 2004, p. 44).

Ao criticarem o conceito de racionalidade tradicional e proporem o de racionalidade situada e procedimental, os regulacionistas superam a dicotomia entre agente-estrutura a partir da ideia de habitus provinda da antropologia. Bourdieu (1997) propôs que o agente social é dotado de um habitus "individual coletivo ou um coletivo individualizado". Assume que os indivíduos possuem características, preferências e gostos formados a partir da sua história e aprendizagem, tanto a coletiva como a individual. O habitus serve para compreender a 
ação humana, pois ela não depende de cálculos maximizadores. Pelo contrário, o habitus é um princípio de ação que reduz a necessidade de esforços cognitivos e, portanto, de tempo.

Como o hábito dá sustentabilidade às instituições, compreende-se que exerce um papel fundamental tanto no plano micro como macroeconômico. No plano das firmas, os hábitos são essenciais para estabilidade das rotinas e da forma de realizar as tarefas, portanto importantes para inovação e evolução tecnológica. Já na visão macroeconômica, o hábito é o que assegura a consistência das formas institucionais. Desta forma, indivíduos, hábitos e instituições estão em constante interação. Como propôs o conceito de reconstitutive downward causation (effect), parte dessa interpretação a explicação do comportamento humano.

A figura a seguir procura sistematizar os elementos da T.R., do institucionalismo derivado de Veblen e da teoria Neoschumpeteriana, sistematizando a proposta de abordagem teórica para analisar o desenvolvimento. Ou seja, sua compreensão não pode se eximir de analisar o progresso técnico, que acontece a partir das firmas (rotinas e inovação), e observar a configuração das formas institucionais (que inclui estado) no estímulo ao aproveitamento das janelas de oportunidade que se abrem em cada revolução tecnológica.

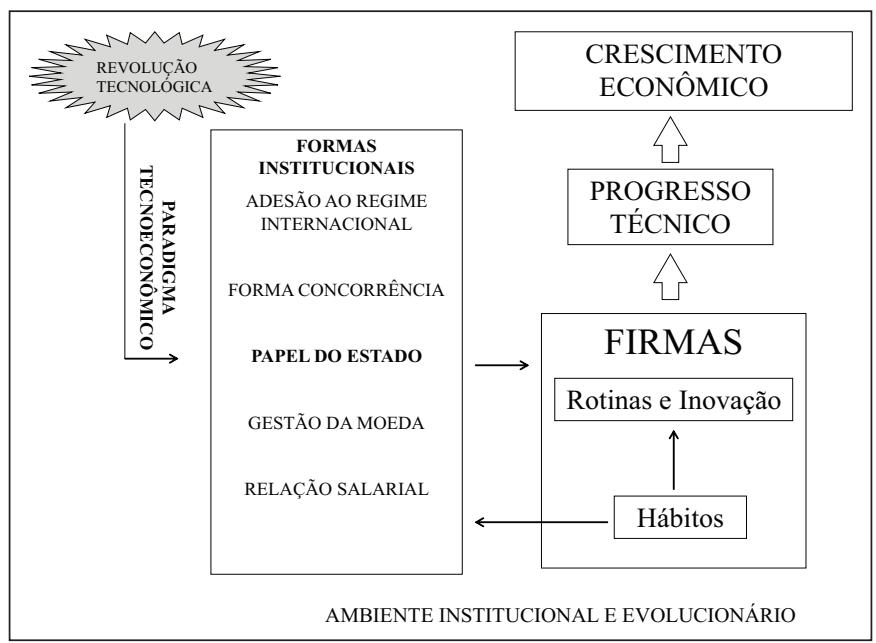

Figura 1 - Proposta de abordagem teórica para analisar o desenvolvimento Fonte: Elaboração Própria 
A ilustração demonstra que o desenvolvimento é uma propriedade emergente que acontece no Plano Macro, a partir das interações microeconômicas. ${ }^{16}$ Sugere que no interior das firmas se desenvolvem rotinas e inovações capazes de proporcionar uma melhor posição de mercado. Ambas são altamente influenciadas pelos hábitos compartilhados dos indivíduos envolvidos no processo produtivo e proporcionam a estabilidade dos comportamentos, a propensão à inovação e os incentivos ao progresso técnico. Os hábitos, na sociedade em geral ou no processo produtivo em específico, ainda são essenciais para configuração das formas institucionais. Por isso, existe um processo de retroalimentação entre as empresas e as formas institucionais, pois ao mesmo tempo em que as firmas se adaptam à regulação, desenvolvem comportamentos que podem reforçar ou agir no sentido de modificar suas características. Não por acaso Perez (1983) afirma que as transformações observadas na esfera produtiva carecem de inovações socioinstitucionais a fim de não prejudicar-se o ritmo de crescimento.

A inovação, as rotinas e as novas tecnologias devem ainda estar em convergência com a revolução tecnológica e com o paradigma tecnoeconômico, proporcionando o aproveitamento da janela de oportunidade aberta em cada momento histórico. A esse respeito, as formas institucionais e a atuação do estado são aspectos de grande relevância, pois devem colocar em evidência uma regulação que estimule a inovação e o progresso tecnológico. Em outras palavras, o catching up é resultado dos hábitos mentais, das rotinas e da inovação, que devem estar em conformidade com a revolução tecnológica em curso. Porém, para acontecer desenvolvimento é preciso que o progresso técnico se dissemine gerando ganhos de produtividade por toda nação, fenômeno muito semelhante ao conceito de "tecnologias sociais" apresentado em Nelson e Sampat (2001) e Nelson (2008). ${ }^{17}$

${ }^{16}$ Segundo Hodgson (1997a), uma propriedade emergente é um conceito característico de um sistema complexo que pode ser descrito em termos macro ou agregando níveis de conceitos, sem referência aos atributos específicos do nível micro. Uma propriedade emergente persiste por períodos de tempo mais significativos que aqueles necessários para descrever as micro-interações. No entanto, o mais importante seria a impossibilidade de ser totalmente explicável em termos das micro-propriedades dos elementos componentes do sistema e suas relações. Conceição (2009) afirma que o conceito de reconstitutive downward causation deve ser utilizado para explicar o crescimento econômico. Nesse sentido, o fenômeno "[...] seria uma propriedade emergente do ambiente micro, centrado nos hábitos, crenças e expectativas de retorno, que se materializaria no plano macro, do agregado que conformaria o paradigma tecnoeconômico vigente" (Conceição, 2009, p. 7).

17 A tecnologia social, que engloba as tecnologias físicas, refere-se a métodos que se sobressaem na forma de fazer as coisas. No plano microeconômico são comportamentos padronizados e 
Portanto, o progresso técnico e sua proliferação apresentam-se como resultado da inovação que acontece no interior das firmas, em consonância com a revolução tecnológica e o paradigma tecnoeconômico em curso, alicerçado nos hábitos mentais dos agentes, que podem se modificar ou permanecer estáveis, dependendo das circunstâncias. Essas novas técnicas proporcionam ganhos significativos de produtividade e se alastram pela sociedade garantindo melhores condições de vida para população.

Cabe ainda destacar que as firmas, seus hábitos, rotinas, capacidade de inovação e tecnologia estão em um processo contínuo de evolução. Ou seja, estão sujeitos a um processo de seleção e adaptação às condições socioeconômicas vigentes. São resultado de um processo histórico de desenvolvimento, por isso inegavelmente path dependence. Não quer dizer que as melhores condições produtivas se estabeleçam ao longo do tempo. Pelo contrário, assim como afirmam os neoschumpeterianos, a matriz institucional é passível de gerar lock in, uma trajetória ineficiente de desenvolvimento que impede o país de aproveitar-se da revolução tecnológica.

No entendimento evolucionário não são apenas as firmas que estão sujeitas à seleção, mas também a tecnologia mais apta. Nelson (2006) afirma que o avanço técnico acontece através da geração de uma série de pontos de partida que concorrem uns com os outros e com as práticas vigentes; uma concorrência em que ganhadores e perdedores são definidos numa luta real. Além do mais, o fato de a tecnologia acabar se tornando pública - e as aptidões de todos serem melhoradas a partir das inovações de alguns - prova que se trata de um processo de evolução cultural (Nelson, 2006). Porém, se o ambiente socioeconômico e as instituições não selecionarem a tecnologia adequada, o catching up se torna mais difícil.

Finalmente, o processo de evolução não é totalmente aleatório. Apesar das limitações cognitivas dos indivíduos e da complexidade do processo de desenvolvimento, os agentes econômicos são seres ativos no processo de mudança e crescimento. A esse respeito nova-

generalizados dos indivíduos no processo produtivo. Por isso estão alavancados nos hábitos, pois, como afirmou Veblen (1983), é a forma de produção vigente em uma sociedade, mesmo ao lado das formas já superadas, que determinam os hábitos mentais. Já no plano macroeconômico, a disseminação tecnológica e as tecnologias sociais são visões muito próximas à ideia de paradigma tecnoeconômico, já que este representa a melhor forma de realizar as tarefas diante da revolução em curso. 
mente cabe destacar a importância do Estado no estímulo ao desenvolvimento tecnológico e evolução das instituições mais eficientes. $\mathrm{O}$ Estado deve estar inserido na atividade econômica, o que significa a definição e redefinição das formas institucionais, a coordenação das políticas macroeconômicas, bem como a formulação de estratégias diretamente relacionadas ao progresso tecnológico. Ainda tem um papel importante na criação de um sistema nacional de inovações (sistema financeiro apropriado, instituições de ensino e pesquisa, etc.) [(Nelson, 2007)] e na geração de infraestrutura que viabilize o progresso técnico em conformidade com a revolução tecnológica (Pérez, 2004).

\section{Considerações finais}

O trabalho apresentou o objetivo de contribuir para compreensão do fenômeno do desenvolvimento ao propor uma abordagem evolucionária/institucionalista que congregou conceitos de três abordagens teóricas: a teoria neoschumpeteriana, o institucionalismo de Veblen e a Teoria da Regulação. Partiu da necessidade de união dessas teorias para interpretar a performance das nações de uma forma consistente.

Observou-se que o desenvolvimento econômico é determinado pelas inovações e progresso tecnológico que ocorre no ambiente micro, mas sob influência da regulação vigente. Trata-se de um processo que pode ser facilitado ou dificultado pela configuração das formas institucionais, que definem condições objetivas para o aproveitamento das oportunidades abertas pelas revoluções tecnológicas. Nesse processo, o estado aparece com papel decisivo, pois pode definir a configuração das formas institucionais e criar estímulos para o surgimento e disseminação das inovações.

Nesta proposta de trabalho observou-se que o crescimento resulta da tecnologia que provém das firmas e é desenvolvida a partir de suas rotinas e inovação. Estas últimas são influenciadas pelos hábitos compartilhados dos indivíduos que atuam no processo produtivo. A noção de hábitos de Veblen ainda dá consistência à análise da sustentação do modo de regulação, que garante a estabilidade na acumulação do capital, os investimentos e a eficácia da inovação. Ou seja, as formas institucionais estão alicerçadas no plano microeconômico e 
sua estabilidade é garantida pelos comportamentos dos indivíduos, que se respaldam nos hábitos mentais.

Enfim, deve-se reconhecer que uma análise mais minuciosa do desenvolvimento deve ainda incorporar elementos que, devido às limitações impostas pela proposta do artigo, não foram discutidos com a devida profundidade. Entre eles estão: o processo de acumulação de capital, o papel dos sistemas nacionais, regionais e setoriais de inovação, o papel das normas formais ou regras, etc. Porém, acredita-se que o texto trouxe importante contribuição, pois pela diversidade institucionalista apresentada pode ser utilizado para interpretar diversos casos de desenvolvimento, inclusive demonstrando as razões de catching up e falling behind das nações. No caso dos países emergentes, a proposta teórica se torna ainda mais relevante. Por não serem precursores da revolução tecnológica, a configuração macroeconômica, em conjunto com os estímulos ao progresso técnico que se processam no âmbito de atuação das firmas, é o que pode permitir o aproveitamento das janelas de oportunidade que surgem em cada revolução.

\section{Referências}

ABRAMOVITZ, M. Catching up, forging ahead and falling behind. Journal of Economic History, New York, v. 46, n. 2, p. 385-406, 1986.

AGLIETTA, M.; ORLEANS, A. A violência da moeda. São Paulo: Editora Brasiliense, 1990.

AMABLE, B. Régulation theory and technical change. In: BOYER, R; SAILLARD, Y. Regulation Theory: The state of the art. Paris : La Découverte \& Syros, 2002.

ANDRE, C. The welfare state and institutional compromises: from origins to contemporary crises. In: BOYER, R; SAILLARD, Y. Regulation Theory: The state of the art. Paris : La Découverte \& Syros, 2002.

BOURDIEU, P. Le champ économique, Actes de la Recherche em Sciences Sociales, nº119, septembre, 1997.

BOYER. R. A teoria da regulação: uma análise crítica. São Paulo: Nobel, 1990.

Perspectives on the wage-labour nexus. In: BOYER, R; SAILLARD, Y. Regulation Theory: The state of the art. Paris : La Découverte \& Syros, 2002b.

BOYER, R; SAILLARD, Y. A summary of regulation theory. In: BOYER, R; SAILLARD, Y. Regulation Theory: The state of the art. Paris : La Découverte \& Syros, 2002.

BRUNO, M. A. P. Crescimento econômico, mudanças estruturais e distribuição as transformações do regime de acumulação no Brasil: uma análise regulacionista. 2004. $711 \mathrm{f}$. Tese (Doutorado em Economia) - Universidade Federal do Rio de Janeiro, Rio de Janeiro, 2004.

Estud. Econ., São Paulo, vol.45, n.2, p.377-400, abr.-jun. 2015 
COMMONS, J. R. Institutional economics. The American Economic Review, Pittsburgh (USA), v. 21, p. $648-657,1931$.

CONCEIÇÃO, O.A.C. Instituições e crescimento econômico: da "tecnologia social” de Nelson à "causalidade vebleniana” de Hodgson. In: ENCONTRO NACIONAL DE ECONOMIA, 37., 2009, Foz do Iguaçu. Anais do $37^{\circ}$ Encontro Nacional de Economia. Disponível em: $<$ https://www.lume. ufrgs.br/bitstream/handle/10183/30422/000732510.pdf? sequence=1>. Acesso em: 10 fev. 2010.

. Instituições, crescimento e mudança na ótica institucionalista. Porto Alegre: Fundação de Economia e Estatística Siegfried Emanuel Heuser (FEE), 2001.

.Crise e regulação: a metamorfose restauradora da reprodução capitalista. Ensaios FEE, Porto Alegre, v. 8, n. 1, p. 155-174, 1987.

CORIAT, B; DOSI, G. The institutional embeddedness of economic change: an appraisal of the 'evolutionary' and 'regulationist' research programmes, 2007. Disponível em http://esnie.org/pdf/ textes_2007/Dosi-chap-12.pdf. Acesso 17 de Jul. de 2013

DEWEY, J. Human Nature and Conduct: an introduction to social psychology. New York: Henry Holt and Company, 1922.

DOSI, G. Sources, Procedures and Microeconomic Effects of Innovation. Journal of Economic Literature. Sept. 26 (3) $1120-1171,1988$.

Technological paradigms and technological trajectories : A suggested interpretation of the determinants and directions of technical change. Research Policy. Elsevier, vol. 22(2), pages 102-103, April, 1993.

FARIA. L. A. E. As formas institucionais de estrutura: do micro ao macro na teoria da regulação. Ensaios FEE, Porto Alegre, v. 22, n. 1, p. 187-204, 2001.

GUTTMANN, R. Money and credit in regulation theory. In: BOYER, R; SAILLARD, Y. Regulation Theory: The state of the art. Paris : La Découverte \& Syros, 2002

HODGSON. G. M. From micro to macro: the concept of emergence and the role of institutions. In: SEMINÁRIO INTERNACIONAL INSTITUIÇÕES E DESENVOLVIMENTO ECONÔMICO: UMA PERSPECTIVA COMPARATIVA SOBRE A REFORMA DO ESTADO, 1997, Rio de Janeiro. Anais do Seminário Internacional Instituições e Desenvolvimento Econômico: uma perspectiva comparativa sobre a reforma do estado. Rio de Janeiro: UFRJ, 1997a.

. The hidden persuaders: institutions and individuals in economic theory. Cambridge Journal of Economics, Oxford, v. 27, n. 2, p. 159-75, mar. 2002.

. Downward causation - some second thoughts. Watford (UK), 2011. Disponível em: $<\mathrm{http}: / /$ www.geoffrey-hodgson.info/downward-causation.htm>. Acesso em: 26 ago. 2011.

. Economia e evolução: o regresso da vida à teoria econômica. Oeiras: Celta, $1997 \mathrm{~b}$.

. Institucional economics: surveying the "old" and the "new". Metroeconomica, Oxford [s. 1.], v. 44 , n. 1, p. 1-28, 1993.

. Choice, Habit and Evolution. Journal of Evolutionary Economics. 20(1), January 2010, pp. 1-18

.What Are Institutions? Journal of economic issues. Vol. XL No. 1. p. 1-25, 2006

. Institutions and individuals: interaction and evolution. Organization Studies, Thousand Oaks (USA), v. 28, n. 1, p. 95-116, 2007b.

HOLLARD, M. Forms of competition. In: BOYER, R; SAILLARD, Y. Regulation Theory: The state of the art. Paris : La Découverte \& Syros, 2002.

KUHN, T. S. A estrutura das revoluções científicas. Tradução de Beatriz Vianna Boeira e Nelson Boeira. 3. ed. São Paulo: Perspectiva, 1992.

LOPES, H. C. Instituições e crescimento econômico: os modelos teóricos de Thorstein Veblen e Douglass North. Revista de Economia Politica. Vol.33, n.4, pp. 619-637, 2013.

NELSON, R. R. As fontes de crescimento econômico. Campinas, SP: Editora da Unicamp, 2006. 
What enables rapid economic progress: what are the needed institutions. Research Policy. N. 37, 2008, p. 1-11

. Economic Development from the perspective of evolutionary economic theory. Working paper series: Globelics, 2007.

NELSON, R.; e WINTER, S. G. In search of useful theory of innovation. Research Police. Elsevier, vol. 6(1), pages 36-76. Janeiro, 1977.

Uma Teoria Evolucionária da Mudança Econômica. Campinas, SP: Editora da Unicamp, 2005.

NELSON, R. R.; SAMPAT, B.N. Las instituiciones como factor que regula el desempeño econômico. Revista de economia institucional, v. 2 nº 005. Bogotá: Colômbia, 2001, p 17-51.

OSER, J. Prefácio da classe ociosa. In: VEBLEN, T. B (1983). A teoria da classe ociosa: um estudo econômico das instituições. São Paulo: Abril Cultural.

PEREZ, C. SOETE, L. Catchin up in technology: entry barriers and Windows of opportunity. In: IN DOSI, G et. All. Technical Change and Economic Theory. Laboratory of Economics and Management (LEM), Sant'Anna School of Advanced Studies, Pisa, Italy, 1988

PEREZ, C. Cambio técnico, restructuración competitiva y reforma institucional en los países en desarrollo. El trimestre económico, México, v. 1, n. 233, p. 23-64, enero/marzo, 1992.

. Cambio estructural y asimilación de nuevas tecnologías en el sistema económico y social. Futures. Vol. 15, Nº 4, Octubre, pp. 357-375, 1983 (Tradução do ingles).

Cambio tecnológico y oportunidades de desarollo como Blanco móvil. Revista de la CEPAL, Santiago de Chile, n. 75, p. 115-136, dic. 2001.

Revoluciones tecnológicas y capital financiero: la dinâmica de las grandes burbujas financieras y las épocas de bonanza. México: Siglo XXI, 2004.

. Technological revolutions and techno-economic paradigms. Working Papers in Technology Governance and Economic Dynamics, no. 20. Technology governance, 2009.

POSSAS, M. L. Economia evolucionária neo-schumpeteriana: elementos para uma integração micro-macrodinâmica. Estudos Avançados av. [online]. 2008, vol.22, n.63, pp. 281-305.

SCHUMPETER, J. A. Capitalismo socialismo e democracia. Rio de janeiro: Fundo de Cultura, 1984. . Teoria do desenvolvimento econômico. São Paulo: Nova Cultural, 1985.

SIMON, H. A. Rationality in psychology and economics. Part 2: The behavioral foundations of economic theory. The Journal of Business, Chicago, v. 59, n. 4, p. 209-224, 1986.

VEBLEN, T. A teoria da classe ociosa: um estudo econômico das instituições. São Paulo: Abril Cultural, 1983.

. The place of science in modern civilization and other essays. New York : Huebsch, 1919.

ZAWISLAK, P.A. Uma abordagem evolucionária para casos de atividade de inovação no Brasil. Ensaios FEE. Porto Alegre, V. 17, nº 1, p. 323-353, 1996. 